\title{
Embedding Exposed Subcutaneous Venous Ports in the Pectoral Muscle: A Practical and Stable Technique for Coverage
}

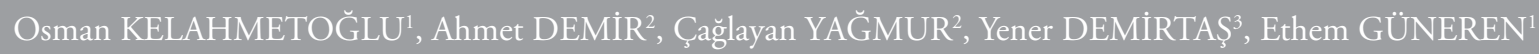 \\ ${ }^{1}$ Department of Plastic, Reconstructive and Aesthetic Surgery, Bezmialem Vakif University School of Medicine, İstanbul, Turkey \\ ${ }^{2}$ Department of Plastic, Reconstructive and Aesthetic Surgery, Ondokuz Mays University School of Medicine, İstanbul, Turkey \\ ${ }^{3}$ LymphEst Plastic Surgery Clinic, İstanbul, Turkey}

\section{ABSTRACT}

Objective: The aim of this study was to present our experience in embedding exposed subcutaneous venous ports in the pectoral muscle.

Methods: In this study, six patients who consulted between January 2006 and November 2013 for exposed subcutaneous venous ports were retrospectively evaluated. The ports were placed in the pectoral muscle.

Results: The patients were followed up for 4-9 months. Oncologic chemotherapies were initiated at the end of the third week after surgery.

Conclusion: With the results of our preliminary observations, we believe that embedding exposed subcutaneous venous ports in the pectoral muscle is a practical and safe method for cachectic patients.

Keywords: Subcutaneous venous port, port exposition, pectoral muscle

\section{Introduction}

Vascular ports, first described in 1982, are catheters that are entirely implanted under the skin and provide safe and easy vascular access for repeated drug applications (1). The implantation of these ports in the angiography chamber using interventional radiological techniques was described in 1992, and radiological port implantation has become increasingly widespread since that time (2). In recent years, the use of central venous access devices, particularly port catheters, has increased because venous access is frequently performed, treatment is time consuming, sclerosant agents are used, and surplus amount of fluid is administered in the treatment of cancer patients (3). Subcutaneous venous ports are subcutaneously placed by interventional radiologists under local anesthesia; through the closed system they create, they allow the delivery of drugs to the bloodstream without the need for repeated vascular access. Moreover, it is preferably used because it does not affect the aesthetic appearance and is convenient to use and patient compliant. In this study, we attempted to present our experiences to correct the complications of subcutaneous venous ports.

\section{Methods}

Between January 2006 and November 2013, six patients who were consulted in our department due to an exposed port and wound disintegration were retrospectively evaluated. The patients in whom the technique was applied were informed about the technique and their written informed consent was obtained for the surgery. The authors read and accepted the rules of ethics published in the "British Medical Journal" of the World Medical Association (Helsinki Declaration) on July 18,1964 . Of the cases who were aged 24-53 years (mean, 34.6 years), four were females and two were males. The reason for placing subcutaneous port in all patients was the need for systemic chemotherapy. The ports were placed in the right subclavicular region of all patients. 

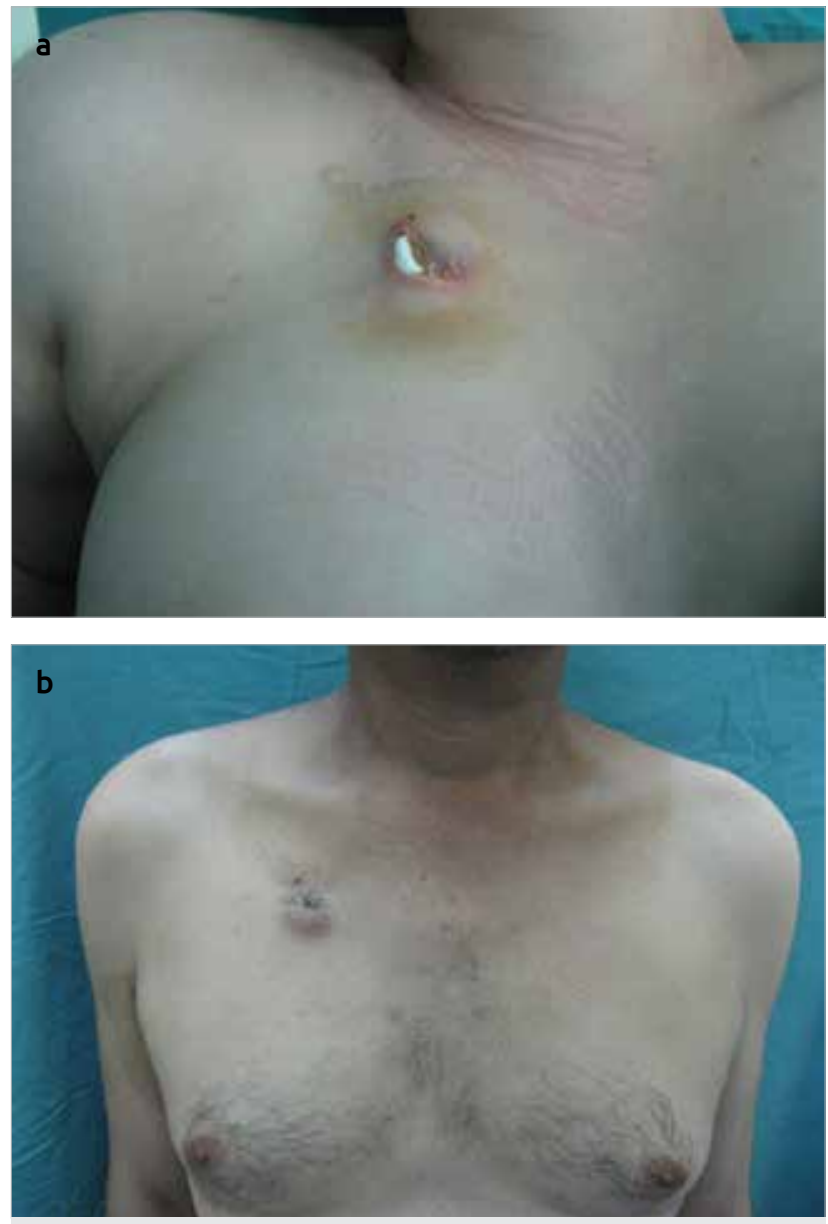

Figure 1. a, b. Exposed port, preoperative view (A) A venous port was placed in a 26 -year-old female patient due to Hodgkin's lymphoma

(B) A venous port was placed in a 37-year-old male patient due to nasopharynx CA
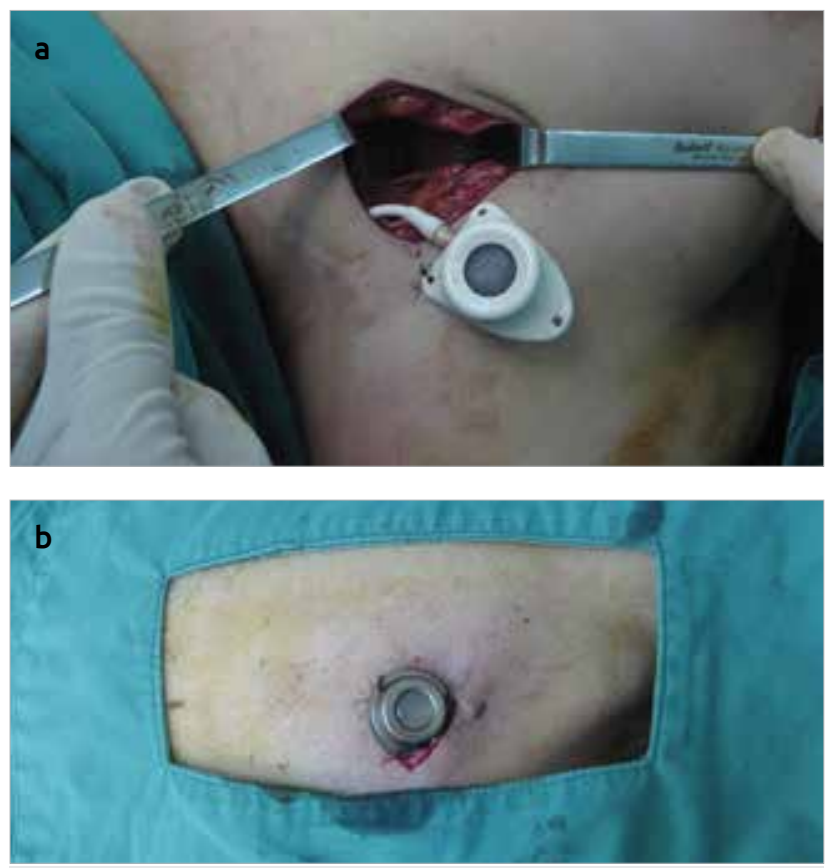

Figure 2. a, b. Release of porttoral muscle
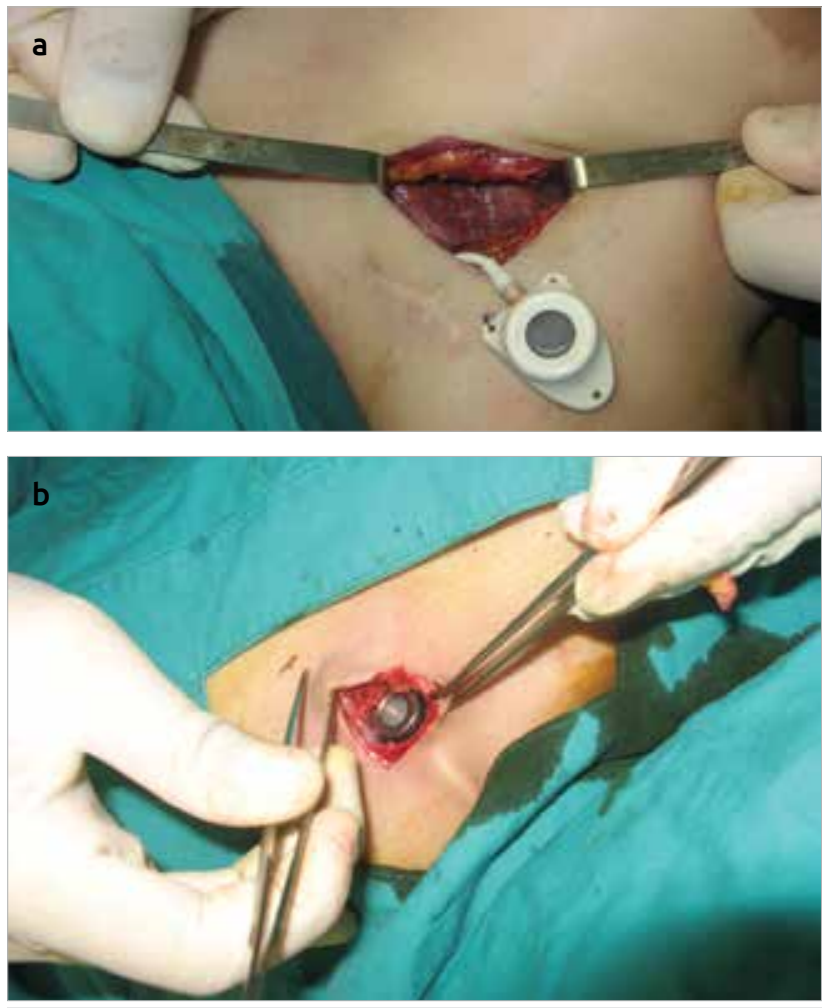

Figure 3. a, b. Creation of a new pocket within the pectoral muscle

\section{Placement in the Pectoral Muscle}

Under local anesthesia, injections were made $5 \mathrm{~cm}$ around the exposed port area (Figure 1a, 1b) and into the pectoral muscle. If there was no contraindication, adrenaline was added to the local anesthetic. First, the tissues in which it was exposed and the wound edges around it were refreshed. By taking the sutures to which the ports were fixed, the ports were released (Figure 3a, 3b). Next, the subcutaneous tissue was opened through blind dissection and the pectoral muscle fascia was reached. After opening the fascia, a new pocket was created parallel to the pectoral muscle fibers (Figures $3 \mathrm{a}$ and $3 \mathrm{~b}$ ), and the port was adapted to the new location. The muscle fascia, the under skin, and the skin were closed according to the procedure (Figure $4 \mathrm{a}, 4 \mathrm{~b}$ ). The drains were placed in patients who could have hemorrhage and were removed on the third day.

\section{Statistical Analysis}

Numbers 2011 for Macintosh (Apple Inc., USA) was used for statistical analysis. Data were presented as mean \pm standard deviation.

\section{Results}

The patients were followed up for 4-9 months. The average follow-up duration was 6.83 months. All surgical procedures were performed under local anesthesia and operating room conditions. Two patients were under treatment for Hodgkin's lymphoma, two for colon cancer, one for breast cancer, and one for nasopharyngeal cancer. After the surgery, the patients 

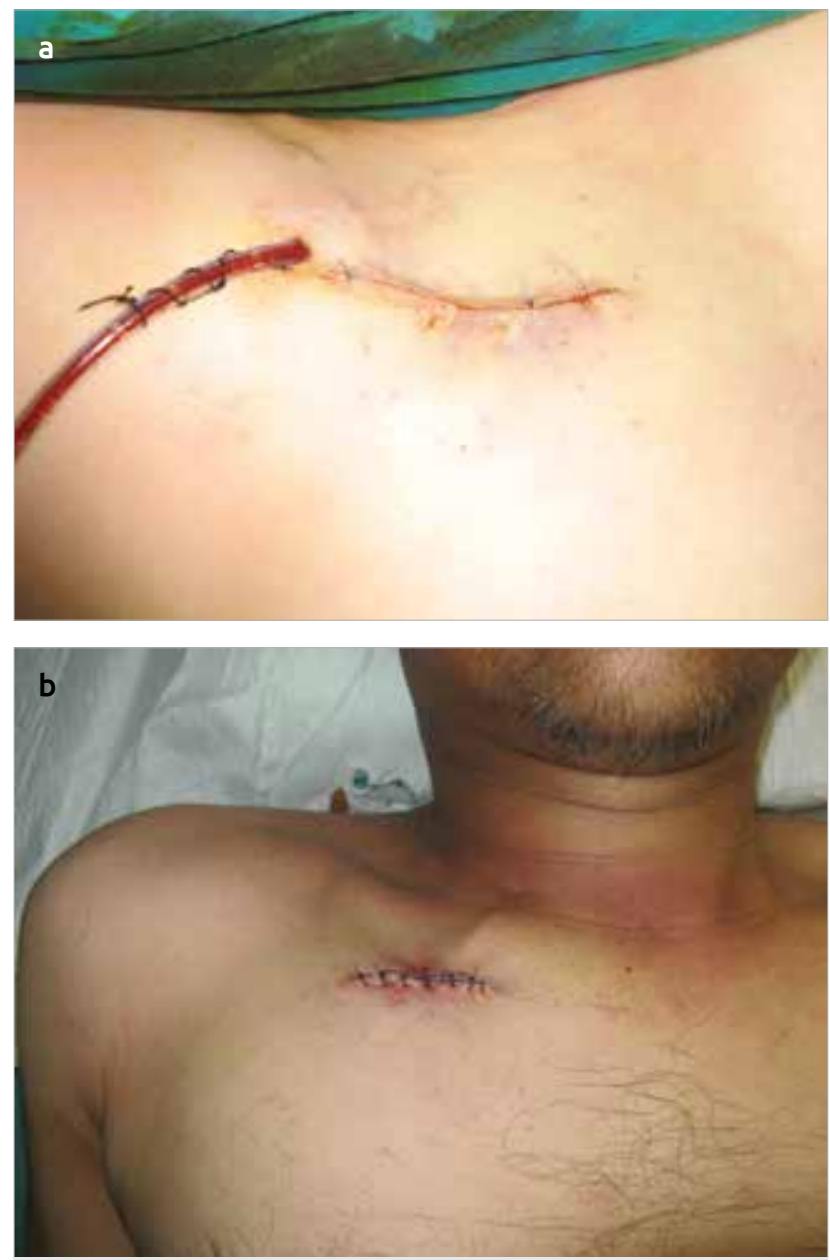

Figure 4. a, b. Postoperative view

were discharged on the same day and oral antibiotics were started and daily dressing was recommended. Sutures were removed at the end of the third week. Surgical field infection, port complication, and recurrence were not observed in the patients who were operated.

\section{Discussion}

Implanted port catheter has many advantages over the other catheters. First, because the appearance is aesthetic, patients can easily prefer the method and adapt. Second, the patients are less anxious because of fewer needle penetrations than the other catheters. A venous access device is preferred by patients due to psycho-social factors, such as convenience in lifestyle, body image, and cosmetic appearance. In addition, besides intravenous drug delivery, it can also be used to withdraw blood for obtaining blood products, total parenteral nutrition, and laboratory tests if necessary (3). It can be placed under local anesthesia and sedation. Prophylactic antibiotics are not routinely used and are used in patients with low white blood cell counts. Before the surgery, the values of complete blood count, biochemical parameters, and bleeding time were evaluated for all patients. Immediately after the surgery, a control chest X-ray was performed to prevent early complications, such as pneumothorax, hemothorax, and port malrota- tion. In the series of Barbaros Erhan Çil et al., the rate of dehiscence developing in the incision line was demonstrated as $0.21 \%$ and the skin necrosis rate was $0.21 \%$ and the port pocket infection rate was $0.42 \%$ (2). Bodner et al. (4) demonstrated that the wound dehiscence rate was $0.9 \%$ and the port pocket infection rate was $8.1 \%$ in a series of 109 patients with peripheral location. Mohsen Rouzrokh et al. (5) compared the results of subcutaneous and subpectoral portals in 524 patients. Although skin necrosis and port exposition were not observed at all in the subpectoral plane, the rates of subcutaneous skin necrosis and port exposition were shown to be $3.2 \%$ and $2.6 \%$, respectively. However, the wound disintegration rate was reported to be $2 \%$ in another study (6). It may also be preferred if the patient has not undergone any surgery in the chest area; has not had an active mediastinal disease, such as Hodgkin's lymphoma; and no radiotherapy and bilateral central vascular access have been used before (7). It has been emphasized that the risk may also increase in patients who have undergone breast cancer surgery (6). In our study, due to Hodgkin's lymphoma, a subcutaneous venous port was placed in two of the six patients who applied with port exposition and in one patient due to breast cancer.

In cancer patients, impaired wound healing, cachexia, thinning of skin layers, and impaired skin blood flow are predisposing factors for port exposition. Repeated needle penetrations can also cause skin injury and consequently result in port exposition. In pediatric patients, placing the ports under the pectoral muscle fascia at the first placement can prevent this complication (5). It is also recommended for the prevention of exposition in elderly cachectic patients (2). If the port is completely or partially exposed, it is an option to remove it in the presence of infection. In the absence of infection, the ports were closed using skin flaps and continued to be used safely (8). In our study, the exposed ports were placed in a pocket created in the pectoral muscle under local anesthesia, particularly in cachectic patients who would receive a long treatment. This option allows both the long-term success of the treatment and the covering of the ports without creating additional morbidity for the patient.

\section{Conclusion}

In cachectic patients who will receive a long-term treatment or in exposed cases, the implantation of subcutaneous venous ports into the pectoral muscle is a simple and safe method.

Ethics Committee Approval: Study done by retrospective data analyses so ethics commitee approval was not taken.

Informed Consent: Informed consent was not obtained because the study is retrospective and there is not any content which reveals the identity of any individual.

Peer-review: Externally peer-reviewed.

Author Contributions: Concept - O.K., A.D., Ç.Y., Y.D., E.G.; Design O.K., A.D., Ç.Y., Y.D., E.G.; Supervision - O.K., A.D., Ç.Y., Y.D., E.G.; Re- 
sources - A.D., Y.D., E.G.; Data Collection and/or Processing - O.K., Ç.Y.; Analysis and/or Interpretation - O.K., Ç.Y., A.D.; Literature Search - O.K., Ç.Y.; Writing Manuscript - O.K., Ç.Y., A.D., Y.D., E.G.; Critical Review O.K., Ç.Y., A.D.

Conflict of Interest: No conflict of interest was declared by the authors.

Financial Disclosure: The authors declared that this study has received no financial support.

\section{References}

1. Kelsaka E, Güldoğuş F. Vasküler Port Uygulamalarımızın Retrospektif Değerlendirilmesi. Uluslararası Hematoloji-Onkoloji Dergisi 2005; 4: 195-8.

2. Çil B E, Canyiğit M, Peynircioğlu B, Hazırolan T, Çarkacı S, Çekirge S, et al. Subcutaneous Venous Port Implantation In Adult Patients: A Single Center Experience. Diagn Interv Radiol 2006; 12: 93-8.

3. Yeşilbalkan Usta Ö. Onkoloji Hastalarında Sık Kullanılan Venöz Giriş Aracı: İmplante Port Kateter. C.Ü. Hemşirelik Yüksek Okulu Dergisi, 2005; 9: 49-54.
4. Bodner LJ, Nosher JL, Patel KM, Siegel RL, Biswal R, Gribbin CE, et al. Peripheral Venous Access Ports: Outcomes Analysis In 109 Patients. Cardiovasc Intervent Radiol 2000; 23: 187-93. [CrossRef]

5. Rouzrokh M, Shamsian BS, Khaleghnejad Tabari A, Mahmoodi M, Kouranlo J, Manafzadeh G, et al. Totally Implantable Subpectoral Vs. Subcutaneous Port Systems In Children With Malignant Diseases. Arch Iran Med 2009; 12: 389-94.

6. Di Carlo I, Cordio S, La Greca G, Privitera G, Russello D, Puleo S, et al. Totally Implantable Venous Access Devices Implanted Surgically: A Retrospective Study on Early and Late Complications. Arch Surg 2001; 136: 1050-3. [CrossRef]

7. Samanci T, Mandel NM, Bozkurt AK, Kutlu F, Uras C. 115 Kanser Hastasında Port Komplikasyonlarının Değerlendirilmesi. Cerrahpaşa Tip Dergisi 2004; 35: 71-7.

8. Toia F, D’Arpa S, Cordova A, Moschella F. Exposed subcutaneous implantable devices: an operative protocol for management and salvage. Plast Reconstr Surg Glob Open 2015; 7: e343. 